\title{
One year of procarbazine lomustine and vincristine is poorly tolerated in low grade glioma: a real world experience in a national neuro-oncology centre
}

Rachel J. Keogh', Razia Aslam¹, Maeve A. Hennessy', Zac Coyne', Bryan T. Hennessy 1,2,3, Oscar S. Breathnach ${ }^{1,2,3}$, Liam Grogan ${ }^{1,2,3}$ and Patrick G. Morris ${ }^{1,2,3^{*}}$ (D)

\begin{abstract}
Background: Following optimal local therapy, adjuvant Procarbazine, Lomustine and Vincristine (PCV) improves overall survival (OS) in low-grade glioma (LGG). However, 1 year of PCV is associated with significant toxicities. In the pivotal RTOG 9802 randomised control trial, approximately half of the patients discontinued treatment after 6 months. As patients on clinical trials may be fitter, we aimed to further explore the tolerability of PCV chemotherapy in routine clinical practice.

Methods: We conducted a retrospective study between 2014 and 2018 at a National Neuro-Oncology centre. Patients who had received PCV during this time period were included. The primary objective was to assess tolerability of treatment. Secondary objectives included evaluation of treatment delays, dose modifications and toxicities.
\end{abstract}

Results: Overall, 41 patients were included, 24 (58\%) were male and 21 (51\%) aged $\geq 40$ years. 38 (93\%) underwent surgical resection and all patients received adjuvant radiotherapy prior to chemotherapy. The median number of cycles completed was 3,2,4 for procarbazine, lomustine and vincristine respectively. Only 4 (10\%) completed all 6 cycles of PCV without dose modifications. There was a universal decline in dose intensity as cycles of chemotherapy progressed. Dose intensity for cycle 1 versus cycle 6 respectively: procarbazine (98\% versus 46\%), lomustine (94\% versus $48 \%$ ) and vincristine (93\% versus 50\%). Haematological toxicities were common. Six (14\%) patients experienced Grade III-IV thrombocytopaenia and 13 (31\%) experienced Grade III-IV neutropaenia.

Conclusion: Toxicities are frequently observed with the PCV regimen in clinical practice. It might be preferable to adjust doses from the start of chemotherapy to improve tolerability or consider alternative chemotherapy, particularly in older patients with LGG.

Keywords: Procarbazine, Lomustine, Vincristine, Chemotherapy, Glioma

\footnotetext{
* Correspondence: patrickmorris@beaumont.ie

'Department of Medical Oncology, Beaumont Hospital, Dublin 9, Ireland

${ }^{2}$ Cancer Clinical Trials and Research Unit, Beaumont Hospital, Dublin 9, Ireland

Full list of author information is available at the end of the article
}

(c) The Author(s). 2021 Open Access This article is licensed under a Creative Commons Attribution 4.0 International License, which permits use, sharing, adaptation, distribution and reproduction in any medium or format, as long as you give appropriate credit to the original author(s) and the source, provide a link to the Creative Commons licence, and indicate if changes were made. The images or other third party material in this article are included in the article's Creative Commons licence, unless indicated otherwise in a credit line to the material. If material is not included in the article's Creative Commons licence and your intended use is not permitted by statutory regulation or exceeds the permitted use, you will need to obtain permission directly from the copyright holder. To view a copy of this licence, visit http://creativecommons.org/licenses/by/4.0/ The Creative Commons Public Domain Dedication waiver (http://creativecommons.org/publicdomain/zero/1.0/) applies to the data made available in this article, unless otherwise stated in a credit line to the data. 


\section{Background}

Low grade gliomas (LGGs) account for 17 to $22 \%$ of primary brain tumours, diffusely infiltrate the central nervous system and cannot be cured by surgery alone [1]. Until recently, the World Health Organisation (WHO) classified LGGs based on histopathological features, and divided them into astrocytoma, oligodendroglioma and oligoastrocytoma, but this was updated in 2019 to include molecular tumour features [2]. Patients with LGG typically present at a younger age, with the peak incidence between 35 and 44 years of age and have longer overall survival (OS) than patients with high grade (IIIIV) gliomas [3, 4]. Given the incurable but indolent nature of these tumours, they pose unique challenges for physicians in terms of treatment decisions and the management of tumour-related and treatment-related sequelae.

In fact, the optimal management of patients with LGG has been one of the most controversial areas in NeuroOncology. For some patients with newly diagnosed tumours, watchful waiting has been an accepted strategy [5]. Conversely, a high-risk group has been defined, including factors such as age $>40$, astrocytoma histology, tumour diameter $>6 \mathrm{~cm}$, tumour crossing the midline and the presence of neurological deficit prior to surgery [6]. Following the decision to operate, these prognostic variables have also been used historically to select patients for more intensive therapy such as radiotherapy and chemotherapy. One of the oldest combinations chemotherapy regimens is $\mathrm{PCV}$, which consists of CCNU (lomustine), procarbazine and vincristine. Previous studies exploring the efficacy of this regimen have mainly focused on high grade tumours [7, 8]. For example, the Radiation Therapy Oncology Group (RTOG)9402 and European Organisation for Research and Treatment of Cancer (EORTC) 26951 studies examined the use of PCV in addition to radiation (RT) compared to RT alone in patients with anaplastic oligodendroglioma (per histological diagnosis) [7, 8]. In both studies, a survival benefit was seen for the RT plus PCV combination arm in patients with $1 \mathrm{p} 19 \mathrm{q}$ co-deleted tumours $[7$, 8].

Against this background the Radiation Therapy Oncology Group (RTOG) conducted the prospective randomised 9802 trial, which was initiated in 1998 and enrolled patient with high-risk LGG, defined as age $>40$ years or with subtotal resection [9]. Patients were randomised to radiation alone 40 Gy in 30 fractions over 6 weeks) or radiation plus PCV chemotherapy every 8 weeks for 6 cycles ( 1 year). This study demonstrated a significant improvement with chemotherapy with a median OS of 13.3 years for patients treated with PCV compared to 7.8 years for the radiation alone group [4]. This magnitude of treatment benefit was considerable and established a new standard of care for LGGs. Despite a planned 6 cycles of treatment in this trial, the median number of cycles completed for procarbazine, lomustine and vincristine was three, four and four respectively [4]. The toxicities recorded were significant. The most clinically relevant of these being myelosuppression, most pronounced for neutrophils and platelets. Specifically, the incidence of grade III and IV haematological toxicity with PCV was 51 and $15 \%$ respectively [4].

It is unknown whether the broader use of the PCV combination in the real world would result in greater toxicity. Therefore, in our study, we aimed to gain a greater understanding of the tolerability of PCV in LGG in routine clinical practice.

\section{Methods}

This was a retrospective study conducted in a national neuro-oncology centre in Ireland. Approval, including a waiver of informed consent was obtained per institutional guidelines. Patients with LGG who were treated with PCV chemotherapy between November 2014 and November 2018 were identified from a pharmacy database. Patient demographics and treatment data were collected from paper and electronic clinical records. As previously reported, the PCV regimen consisted of procarbazine $\left(60 \mathrm{mg} / \mathrm{m}^{2}\right.$ formulated in $50 \mathrm{mg}$ capsules $)$ orally day $8-21$, lomustine $\left(110 \mathrm{mg} / \mathrm{m}^{2}\right.$ in $40 \mathrm{mg}$ capsules) orally on day 1 , and vincristine $\left(1.4 \mathrm{mg} / \mathrm{m}^{2}\right.$, capped at 2 $\mathrm{mg}$ ) intravenously on day 8 and day 29 of each 56 day cycle [4]. Patients underwent dose reductions and delays as per standard of care.

The primary objective of the study was tolerability of treatment, as assessed by the number of patients completing all planned treatment without any dose omissions. Secondary objectives included treatment delays, dose modifications and the evaluation of toxicities graded as per CTCAE version 4 [10]. Data were collected for the overall population and using the age 40 as a cut-off as previously reported by Buckner et al. [4]. For the primary objective, the number of patients who had 1 or more drugs omitted was expressed as a percentage of the total number of patients for each cycle of PCV. Dose intensity was calculated for each chemotherapeutic agent by cycle as a percentage of the total calculated dose that was actually administered. Dose omissions, dose delays and reductions were recorded for each chemotherapy agent for each cycle of PCV. Data were collected using Microsoft Excel and statistical analysis was performed using Excel and SPSS ${ }^{\mathrm{mw}}$ version 26 software. Patient characteristics were reported as median for continuous variables, and frequencies and percentages were calculated for categorical variables. Baseline characteristics of those aged $<40$ years were compared to those who were aged 40 and above were tested for dependence using chi- 
square test. Fisher's exact was used when the expected frequencies proved to be too small.

\section{Results}

\section{Patient characteristics}

A total of 45 patients with LGG who received PCV chemotherapy were identified. Four patients were excluded: one had no prior radiotherapy, one had chemotherapy in another institution and two had additional radiotherapy in the preceding 5 years. Therefore, 41 patients were included in the study. Most (58\%) patients were male (Table 1). There was a similar number of

Table 1 Patient Baseline Characteristics

\begin{tabular}{|c|c|c|c|c|c|c|c|}
\hline & \multicolumn{2}{|c|}{$\begin{array}{l}\text { Age }<40 \\
N=20\end{array}$} & \multicolumn{2}{|c|}{$\begin{array}{l}\text { Age } \geq 40 \\
N=21\end{array}$} & \multicolumn{2}{|c|}{$\begin{array}{l}\text { Total } \\
N=41 \\
\text { (\%) }\end{array}$} & \multirow[t]{2}{*}{$\begin{array}{l}p \text { - } \\
\text { value }\end{array}$} \\
\hline & $\mathbf{N}$ & $\%$ & $\mathbf{N}$ & $\%$ & $\mathbf{N}$ & $\%$ & \\
\hline Sex: & & & & & & & $0.412^{a}$ \\
\hline Male & 13 & 65 & 11 & 52 & 24 & 58 & \\
\hline Female & 7 & 35 & 10 & 48 & 17 & 41 & \\
\hline Recurrent/First Diagnosis: & & & & & & & $0.427^{\mathrm{a}}$ \\
\hline First Diagnosis & 12 & 60 & 10 & 48 & 22 & 54 & \\
\hline Recurrent & 8 & 40 & 11 & 52 & 19 & 46 & \\
\hline Surgery: & & & & & & & $1.00^{\mathrm{b}}$ \\
\hline Resection & 18 & 90 & 20 & 95 & 38 & 93 & \\
\hline Biopsy & 2 & 10 & 1 & 5 & 3 & 7 & \\
\hline Histology: & & & & & & & $0.002^{\mathrm{a}}$ \\
\hline Oligodendroglioma & 9 & 45 & 19 & 90 & 28 & 68 & \\
\hline Astrocytoma & 11 & 55 & 2 & 9 & 13 & 32 & \\
\hline IDH: & & & & & & & $1.00^{\mathrm{b}}$ \\
\hline Mutated & 19 & 95 & 19 & 90 & 38 & 93 & \\
\hline Wildtype & 0 & 0 & 0 & 0 & 0 & 0 & \\
\hline Unknown & 1 & 5 & 2 & 9 & 3 & 7 & \\
\hline 1p19q Co-deletion: & & & & & & & $0.001^{a}$ \\
\hline Present & 7 & 35 & 18 & 86 & 25 & 61 & \\
\hline Absent & 10 & 50 & 2 & 9 & 12 & 29 & \\
\hline Unknown & 3 & 15 & 1 & 5 & 4 & 10 & \\
\hline \multicolumn{8}{|l|}{ MGMT } \\
\hline Methylated & 8 & 40 & 6 & 29 & 14 & 34 & \\
\hline Unmethylated & 1 & 5 & 0 & 0 & 1 & 2.4 & \\
\hline Unknown & 11 & 55 & 15 & 71 & 26 & 63 & \\
\hline \multicolumn{8}{|l|}{ ATRX } \\
\hline Mutated & 5 & 25 & 1 & 5 & 6 & 15 & \\
\hline Wildtype & 3 & 15 & 8 & 38 & 11 & 27 & \\
\hline Unknown & 12 & 60 & 12 & 57 & 24 & 58 & \\
\hline
\end{tabular}

Each value is represented by number of patients $(\mathrm{N})$ and percentage of patients (\%)

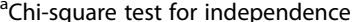

${ }^{\mathrm{b}}$ Fisher's exact test patients that were aged $<40(n=20)$ and $\geq 40$ years $(n=$ 21 ). The predominant histopathological subtype was oligodendroglioma (68\%). The vast majority (93\%) of patients underwent surgical resection (rather than biopsy alone) prior to chemotherapy and all patients underwent adjuvant radiotherapy prior to initiation of chemotherapy. The majority of tumours had some favourable biology, 93\% had IDH mutation and 61\% 1p19q co-deletion. Notable differences between those under 40 years old and those aged 40 and above include histological subtype and the presence of $1 \mathrm{p} 19 \mathrm{q}$ codeletion (Table 1 ). The histological diagnosis of oligodrendroglioma was more common in those aged 40 and above $(90 \%$ versus $45 \%, p=0.002)$ and accordingly, $1 \mathrm{p} 19$ codeletion was therefore more likely to be present (86\% versus $35 \%$, $p=0.001$ ).

\section{Treatment delivered}

Twenty (48\%) patients completed all 6 cycles of treatment. Only four (10\%) patients completed all 6 cycles without any dose modifications. The median number of cycles completed of procarbazine, lomustine and vincristine was three, two and four respectively. The number of dose omissions increased as patients progressed from cycle 1 to cycle 6 (Fig. 1). In cycle 1, at least one dose was omitted in $17 \%$ of patients, but this rose to 29 and $34 \%$ in cycles 4 and 6 respectively. In addition, 15 and $27 \%$ patients had discontinued all treatment doses by cycle 4 and 6 respectively (Fig. 1).

The dose intensity for each chemotherapy agent decreased from cycle 1 to cycle 6 (Fig. 2a). The dose intensity for procarbazine dropped from $98 \%$ in cycle 1 to $68 \%$ in cycle 4 and $46 \%$ in cycle 6 . Similarly, the dose intensity of lomustine dropped from $94 \%$ in cycle 1 to $74 \%$ in cycle 4 and $48 \%$ in cycle 6 . For patients under the age of 40 , the dose intensity for procarbazine, lomustine and vincristine was 98,92 and $90 \%$ respectively in cycle 1 . By cycle 6 , the dose intensity for these three agents was 62 , 56 and $67 \%$ respectively (Fig. 2 b). This decline was even more evident in patients aged 40 years and above, for whom cycle 6 dose intensity was only 39, 41 and 50\% for the three agents respectively (Fig. 2c).

There was a consistent trend towards more dose reductions and omissions with increased cycles (Fig. 3). The percentage of patients who received the full dose of each drug for Cycle 1 as compared to Cycle 6 was as follows; procarbazine $98 \%$ versus $27 \%$, lomustine $98 \%$ versus $17 \%$, and vincristine $71 \%$ versus $34 \%$. There were no dose reductions in Cycle 1 however by Cycle 6, 34\% had a dose reduction of procarbazine, $49 \%$ had a dose reduction of lomustine and 5\% had a dose reduction of vincristine. Only $2 \%$ of patients did not receive procarbazine or lomustine for Cycle 1, but this increased to 39 and $34 \%$ respectively for cycle 6 . Overall, $60 \%$ of 


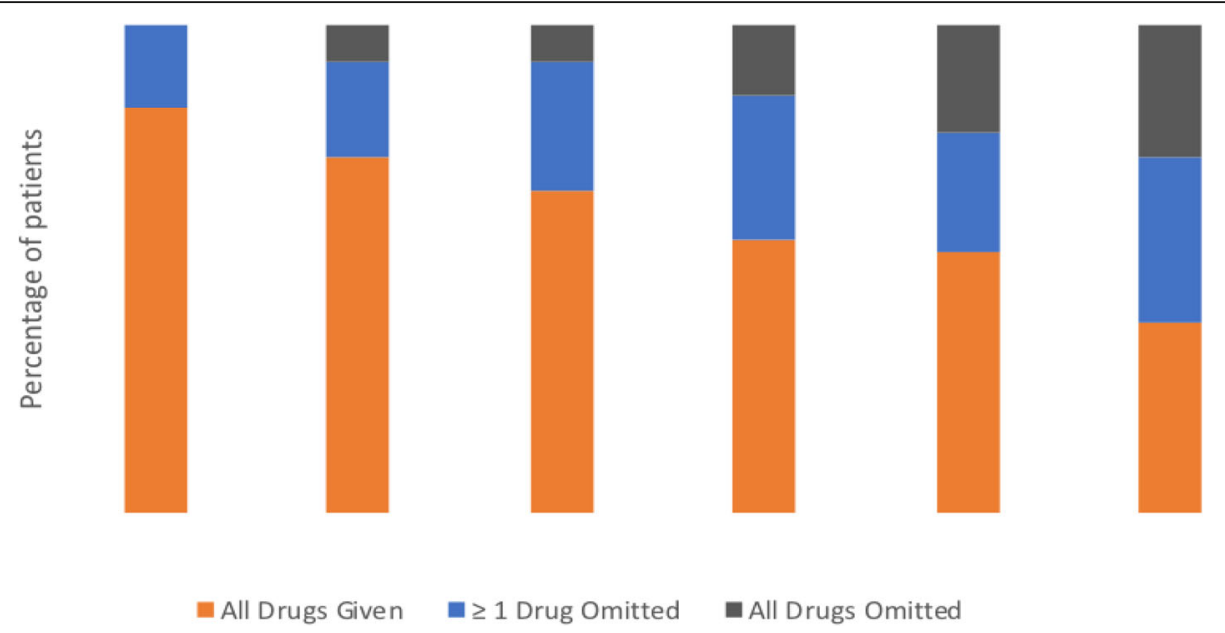

Fig. 1 Treatment administered by PCV cycle. Data expressed as a percentage of patients who had all drugs given (orange), $\geq 1 \geq 1$ drug omitted (blue), all drugs omitted (grey)

patients did not receive Vincristine for Cycle 6. Patients 40 and above received more dose reductions and dose omissions compared to those under 40 years of age for each of the three agents (Fig. 3b/c).

\section{Toxic effects}

Overall, 21 (51\%) patients had treatment discontinued prematurely. The most common reason for this was haematological toxicity, which occurred in 14 (66\%) patients. In addition, 5 (24\%) patients discontinued treatment due to non-haematological toxicity and two (9\%) discontinued due to disease progression. In terms of haematological toxicities, $5(12 \%)$ and 1 (2\%) patients had Grade III and IV thrombocytopenia respectively. 10 (24\%) and 3 (7\%) patients had grade III and IV neutropaenia respectively. Table 2 summarises nonhaematological toxicities recorded in our study most notably Grade I/II fatigue which occurred in 59\% of cases.

\section{Discussion}

This retrospective study conducted over a five-year period in a tertiary neuro-oncology centre provides important 'real-world' data on the tolerability of PCV chemotherapy in routine clinical practice. Our study confirms that frequent toxicities occur with the PCV regimen with implications for treatment tolerability. Less than half of the patients completed all 6 cycles and $10 \%$ of patients completed all 6 cycles without dose modifications, primarily because of haematological toxicity. Additionally, the number of dose reductions and dose delays increased as treatment progressed highlighting the associated toxicity and poor tolerability of this chemotherapy regimen. Perhaps unsurprisingly, PCV appeared to be less well tolerated in patients aged 40 and above, with a higher rate of dose reductions and dose delays seen in this cohort as compared to their younger counterparts, as well as a reduction in dose intensity. This likely reflects the better performance status of patients under the age of 40 and age is itself an independent risk factor for poor prognosis in LGG [6].

Patients with LGG have a longer survival than those with high grade tumours with a median survival of 13 years with intensive treatments [4]. Therefore, treatment toxicities are a critical consideration when determining the most appropriate therapeutic strategy. Given the relative longevity associated with these tumours, it is essential that treatment toxicities are carefully considered when making treatment decisions and managing tumour-related and treatment-related sequelae. In terms of non-haematological toxicities, we found that there was a higher incidence of Grade III nausea recorded in our study compared to the RTOG 9802 (5\% versus $2 \%$ ) [4]. However, Grade III fatigue was reported in $8 \%$ of cases in the RTOG 9802 trial compared $2 \%$ of cases in our study [4]. The RTOG 9802 had higher rates of Grade I/II non-haematological toxicities, which may reflect the fact that often less severe adverse events may be under-reported or not rigorously recorded in routine clinical practice. Although the incidence of peripheral neuropathy was not specifically recorded in the RTOG 9802 trial it should be noted that a high percentage of patients in our study experienced this (32\%).

Our study found a higher rate of premature treatment discontinuation due to toxicity compared to the EORTC 26951 trial (46\% versus 38\%) [11]. Similar rates of grade III/grade IV neutropaenia and thrombocytopenia were reported when comparing our study to the EORTC 26951 trial (30\% versus 32\%, 17\% versus $21 \%$ ) [11]. In the RTOG-9402 trial, PCV was administered in an 


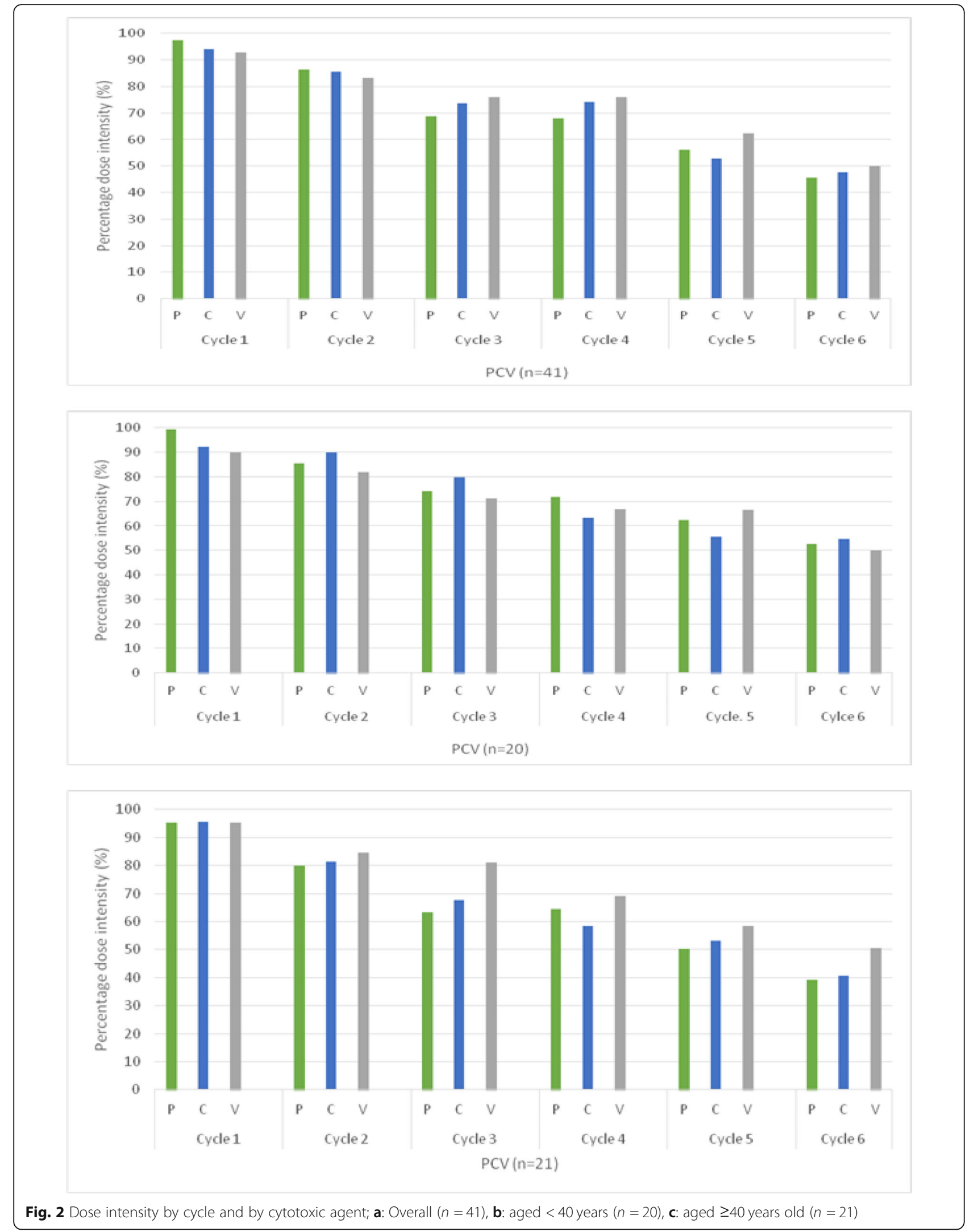



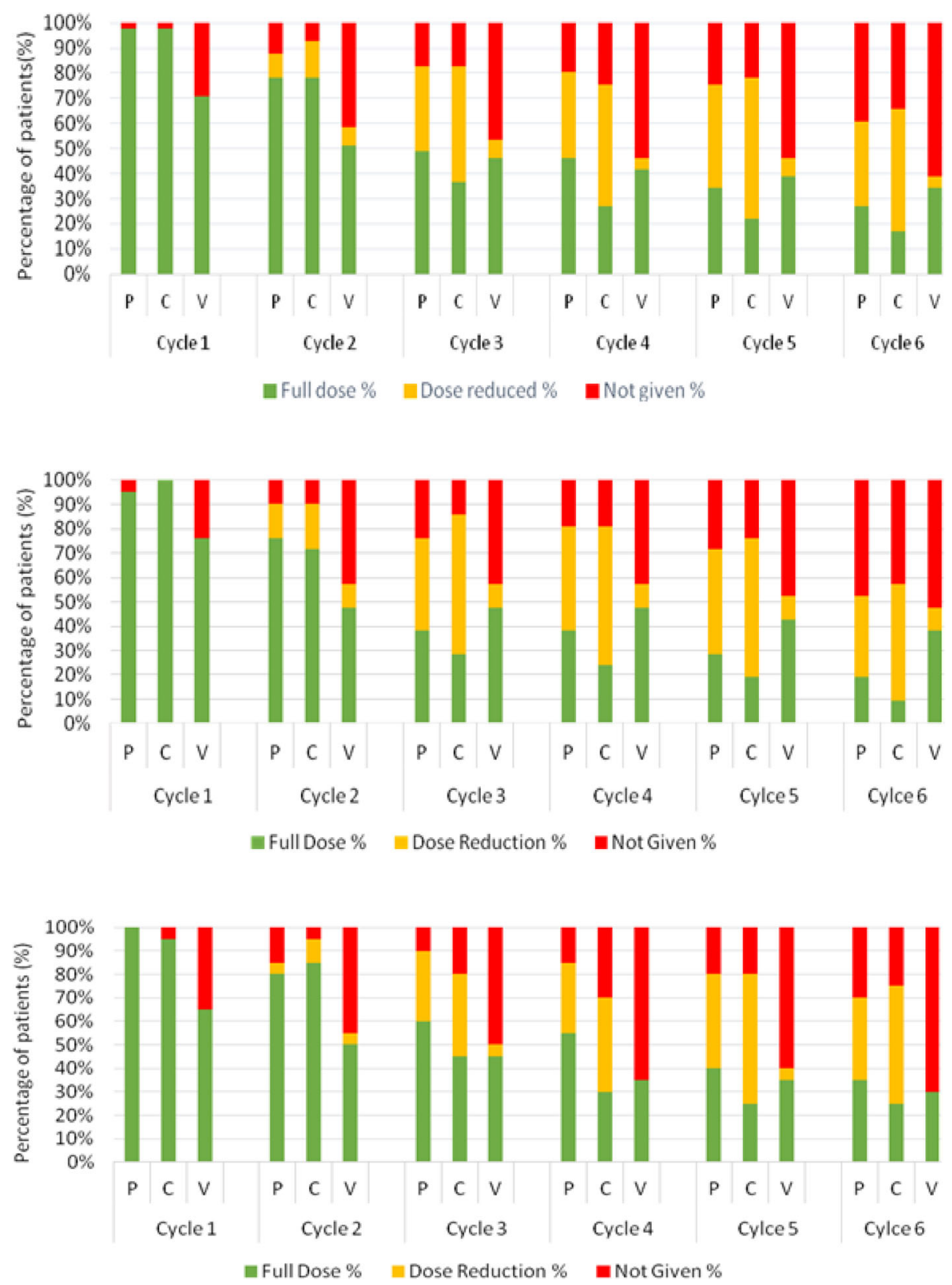

Fig. 3 Percentage of patients who received full dose (green), dose reduction (yellow) and dose omission or delay (red) for each agent for each cycle of PCV. a: overall group $(n=41), \mathbf{b}$ : $<40$ years old $(n=20), \mathbf{c} \geq 40$ years old $(n=21)$

Table 2 Most Common Toxicities

\begin{tabular}{|c|c|c|c|c|}
\hline & Grade 1 & Grade 2 & Grade 3 & Grade 4 \\
\hline \multicolumn{5}{|l|}{ Haematological } \\
\hline Thrombocytopaenia & 36 & 18 & 5 & 1 \\
\hline Neutropaenia & 27 & 21 & 10 & 3 \\
\hline \multicolumn{5}{|l|}{ Non-Haematological: } \\
\hline Fatigue & 17 & 7 & 1 & - \\
\hline Gastrointestinal symptoms (anorexia, nausea) & 15 & 7 & 1 & - \\
\hline Peripheral Neuropathy & 11 & - & 2 & - \\
\hline
\end{tabular}

Each value is represented by the number of patients that experience each toxicity $(\mathrm{N})$ 
intensified regimen of 4 cycles of PCV every 6 weeks prior to RT, given at lomustine $130 \mathrm{mg} / \mathrm{m}^{2}$ orally on day 1 ; procarbazine $75 \mathrm{mg} / \mathrm{m}$ daily, days 8 through 21 ; and vincristine $1.4 \mathrm{mg} / \mathrm{m}^{2}$ intravenously on days 8 and 29 with no $2 \mathrm{mg}$ limit on vincristine [12]. PCV was stopped prematurely in $20 \%$ of cases in the RTOG-9402 study due to toxicity [12]. In this dose-intense regimen, the rate of grade 3 and 4 toxicity was significant (33 and $32 \%$ respectively) with 80 of 144 patients in the PCV-RT arm experiencing severe haematological toxicity and two early deaths in the PCV-arm due to PCV-induced neutropaenia $[7,12]$. Due to the adverse safety profile, the use of this dose-intense regimen is not seen in routine clinical practice. In the EORTC 26951 study, premature treatment discontinuation occurred in $38 \%$ of patients because of haematological toxicity (33\%) or nonhaematological toxicity (5\%) [8].

The considerable number of dose reductions and dose omissions in our study, coupled with the fact that just over half of patients had treatment discontinued prematurely, supports the argument for adjusting doses from the outset of chemotherapy to improve tolerability. The impact of this on patient outcomes is unclear. Whether or not an alternative treatment strategy may be more suitable in patients with LGG remains to be seen. Temozolomide is easier to administer with better patient tolerance and it has improved survival in high grade glioma. It therefore has replaced PCV in more recent trials because of its improved toxicity profile and the expectation that both alkylating-based therapies would prove similarly efficacious. However, a direct comparison of the two regimens in this setting has yet to be completed. In the NOA-04 study, patients with newly diagnosed anaplastic gliomas were randomised to upfront RT or upfront chemotherapy (PCV or temozolomide) [13]. At progression, patients randomised to RT were treated with chemotherapy and those treated with upfront chemotherapy were treated with RT. Patients with $1 \mathrm{p} / 19 \mathrm{q}$-codeleted tumours treated with temozolomide upfront had a worse outcome compared to those treated with PCV regimen with a PFS of 4.46 years in the TMZ arm compared to 9.4 years in the PCV arm and OS of 8.09 years in the TMZ arm and not reached in PCV arm [13]. Primary chemotherapy (PCV or temozolomide) was inferior to upfront RT [13]. A potential hypothesis for the inferiority of temozolomide in the concern that temozolomide may lead to a hypermutatable phenotype. Johnson et al. performed genome sequence analysis of initial and recurrent gliomas with or without exposure to TMZ [14]. Patients with tumours previously treated with TMZ were hypermutated at recurrence in a greater proportion of TMZ-exposed patients [14]. The resulting genetic changes resembled those found in glioblastoma raising the possibility that TMZ could accelerate tumour transformation to a more aggressive phenotype. One of the limitations of this study is the lack of a PCV arm to compare the genetic alterations identified in recurrent tumours. The longest ongoing clinical trial comparing PCV versus TMZ in oligodendrogliomas is the Phase III CODEL trial which has reopened as a two-arm comparison of either RT followed by PCV or RT with concurrent and adjuvant temozolomide and the results of this are eagerly awaited [15]. This study includes both grade II and grade III oligodendrogliomas.

As more treatment options for low-grade gliomas become available, quality-of-life measures and outcomes will play key roles in management recommendations. Future therapies will be focused not only on improving survival but also on quality of life. As we move towards molecular profiling of tumours, more targeted and personalised treatments will hopefully be available and our treatment strategies will be altered accordingly.

Some of the limitations of this study should be noted. First, the sample size is relatively small, although this series still represents a large series given the rarity of the tumour. In addition to this, this is a retrospective study, which was unable to assess the impact of treatment on cognition and quality of life. Grade I and Grade II nonhaematological toxicities may have been under-reported as we relied on retrospective clinical records for this information, rather that multiple additional data-points, which might have been collected in a clinical trial. Dose reductions may also not have been as rigorously or as consistently applied as in the RTOG 9802 trial. As such, data derived from this analysis should be interpreted cautiously.

In summary, our study confirms the earlier findings of the RTOG 9802 trial that the PCV regimen is poorly tolerated in routine clinical practice and demonstrates that toxicities are frequently observed. Furthermore, there was a notable difference in the treatment tolerability of PCV in those aged greater than 40. It might be preferable to adjust doses from the start of chemotherapy to improve tolerability or consider alternative chemotherapy, particularly in older patients with LGG.

\section{Abbreviations \\ PCV: Procarbazine, lomustine, vincristine; OS: Overall survival; RTOG: Radiation Therapy Oncology Group; LGG: Low grade glioma; WHO: World Health \\ Organisation; EORTC: European Organisation for Research and Treatment of Cancer (EORTC); CTCAE: Common Terminology Criteria for Adverse Events; RT: Radiation therapy; TMZ: Temozolomide}

\section{Acknowledgements}

None.

\section{Authors' contributions}

All authors contributed to the study conception and design. Material preparation, data collection and analysis were performed by RJK, RA, and MAH. Patients were supplied by BH, LG, OSB, PGM. The first draft was written by RJK, MAH, ZC and PGM. All authors read and approved the final manuscript. 


\section{Funding}

No funding was obtained for this study.

\section{Availability of data and materials}

The data that support the findings of this study are available from the corresponding author on reasonable request.

\section{Ethics approval and consent to participate}

The study was approved by the Audit office at Beaumont Hospital, Dublin, Ireland. This approval included all administrative permissions necessary to access and use the study administrative data. As a retrospective study, no informed consent was obtained. This is in compliance with National Guidelines as indicated by the Health Research Consent Declaration Committee on Retrospective Chart Review (Updated August 30th, 2019) [16].

\section{Consent for publication}

Not applicable.

\section{Competing interests}

PGM received travel support from Roche, Novartis, Amgen. PGM received honoraria from Astellas, Novartis, Pfizer, Teva, Nordic, Bristol Meyers Squibb, Astra Zeneca, Genomic health, Roche. PGM has a consultancy/advisory role with Novartis. PGM has had a speaker role with Teva. PGM received research funding from Teva and Genomic Health however no funding was obtained for this study. All other authors declare that they have no competing interests.

\section{Author details}

'Department of Medical Oncology, Beaumont Hospital, Dublin 9, Ireland. ${ }^{2}$ Cancer Clinical Trials and Research Unit, Beaumont Hospital, Dublin 9, Ireland. ${ }^{3}$ Royal College of Surgeons Ireland, Dublin, Ireland.

Received: 24 October 2020 Accepted: 13 January 2021

Published online: 08 February 2021

\section{References}

1. Brown TJ, Bota DA, van Den Bent MJ, Brown PD, Maher E, Aregawi D, et al. Management of low-grade glioma: a systematic review and meta-analysis. Neuro Oncol Pract. 2018;6(4):249-58.

2. Louis DN, Perry A, Reifenberger G, von Deimling A, Figarella-Branger D, Cavenee WK, et al. The 2016 World Health Organization classification of tumors of the central nervous system: a summary. Acta Neuropathol. 2016; 131(6):803-20.

3. Ostrom OT, Gittleman H, Fulop J, Liu M, Blanda R, Kromer C, et al. CBTRUS Statistical Report: Primary Brain and Central Nervous System Tumors Diagnosed in the United States in 2008-2012. Neuro-Oncology. 2015 17(Suppl 4):iv1-iv62.

4. Buckner JC, Shaw EG, Pugh SL, Chakravarti A, Gilbert MR, Barger GR, et al. Radiation plus Procarbazine, CCNU, and vincristine in low-grade Glioma. N Engl J Med. 2016;374(14):1344-55.

5. Shaw EG, Berkey B, Coons SW, Bullard D, Brachman D, Buckner JC, et al. Recurrence following neurosurgeon-determined gross-total resection of adult supratentorial low-grade glioma: results of a prospective clinical trial. J Neurosurg. 2008;109(5):835-41.

6. Pignatti F, van den Bent M, Curran D, Debruyne C, Sylvester R, Therasse P, et al. Prognostic factors for survival in adult patients with cerebral low-grade glioma. J Clin Oncol. 2002;20(8):2076-84.

7. Cairncross G, Wang M, Shaw E, Jenkins R, Brachman D, Buckner J, et al. Phase III trial of chemoradiotherapy for anaplastic oligodendroglioma: longterm results of RTOG 9402. J Clin Oncol. 2013;31(3):337-43.

8. van den Bent MJ, Brandes AA, Taphoorn MJ, Kros JM, Kouwenhoven MC Delattre JY, et al. Adjuvant procarbazine, lomustine, and vincristine chemotherapy in newly diagnosed anaplastic oligodendroglioma: long-term follow-up of EORTC brain tumor group study 26951. J Clin Oncol. 2013; 31(3):344-50.

9. Shaw EG, Wang M, Coons SW, Brachman DG, Buckner JC, Stelzer KJ, et al. Randomized trial of radiation therapy plus procarbazine, lomustine, and vincristine chemotherapy for supratentorial adult low-grade glioma: initial results of RTOG 9802. J Clin Oncol. 2012;30(25):3065-70.
10. National Institutes of Health NCl, U.S.Department of Health and Human Services. Common Terminology Criteria for Adverse Events (CTCAE). 2009; Version 4.0.

11. van den Bent MJ, Carpentier AF, Brandes AA, Sanson M, Taphoorn MJB, Bernsen HJJA, et al. Adjuvant Procarbazine, Lomustine, and vincristine improves progression-free survival but not overall survival in newly diagnosed anaplastic Oligodendrogliomas and Oligoastrocytomas: a randomized European Organisation for Research and Treatment of Cancer phase III trial. J Clin Oncol. 2006;24(18):2715-22.

12. Cairncross G, Berkey B, Shaw E, Jenkins R, Scheithauer B, Brachman D, et al. Phase III trial of chemotherapy plus radiotherapy compared with radiotherapy alone for pure and mixed anaplastic Oligodendroglioma: intergroup radiation therapy oncology group trial 9402. J Clin Oncol. 2006; 24(18):2707-14.

13. Wick W, Roth P, Hartmann C, Hau P, Nakamura M, Stockhammer F, et al. Long-term analysis of the NOA-04 randomized phase III trial of sequential radiochemotherapy of anaplastic glioma with PCV or temozolomide. Neuro Oncology. 2016;18(11):1529-37.

14. Johnson BE, Mazor T, Hong C, Barnes M, Aihara K, McLean CY, et al. Mutational analysis reveals the origin and therapy-driven evolution of recurrent glioma. Science. 2014;343(6167):189-93.

15. Jaeckle K, Vogelbaum M, Ballman K, Anderson SK, Giannini C, Aldape K, et al. CODEL (Alliance-N0577; EORTC-26081/22086; NRG-1071; NCIC-CEC-2): Phase III Randomized Study of RT vs. RT+TMZ vs. TMZ for Newly Diagnosed 1p/19q-Codeleted Anaplastic Oligodendroglial Tumors. Analysis of Patients Treated on the Original Protocol Design (PL02.005). Neurology. 2016;86(16 Supplement) PL02.005.

16. Author N. Health Research consent declaration committee: retrospective chart reviews [updated April 30th 2019]. Available from: https://hrcdc.ie/ retrospective-chart-reviews/.

\section{Publisher's Note}

Springer Nature remains neutral with regard to jurisdictional claims in published maps and institutional affiliations.

Ready to submit your research? Choose BMC and benefit from:

- fast, convenient online submission

- thorough peer review by experienced researchers in your field

- rapid publication on acceptance

- support for research data, including large and complex data types

- gold Open Access which fosters wider collaboration and increased citations

- maximum visibility for your research: over $100 \mathrm{M}$ website views per year

At BMC, research is always in progress.

Learn more biomedcentral.com/submissions 